\title{
Práticas pedagógicas de Educação Popular em Saúde e a formação técnica de Agentes Comunitários de Saúde no município do Rio de Janeiro, Brasil
}

Kátia Mendes de Souza(a) Irene Leonore Goldschmidt(b)

Vera Joana Bornstein ${ }^{(\mathrm{c})}$ Sonia Acioli ${ }^{(d)}$

\section{Introdução}

Em 2004, os Ministérios da Saúde e da Educação publicaram o Referencial Curricular para o curso técnico de Agente Comunitário de Saúde ${ }^{1}$, organizado em três módulos, com a duração mínima de mil e duzentas horas. Essa formação do Agente Comunitário de Saúde (ACS) se constitui numa proposta de habilitação técnica que se fundamenta na importância desse trabalhador de saúde para a consolidação da Política Nacional de Atenção Básica. No entanto, apenas o primeiro módulo é financiado pelo Ministério da Saúde, e, na maioria dos estados brasileiros, não tem sido garantida a formação técnica completa dos agentes.

No período de 2005 a 2007, a Escola de Formação Técnica em Saúde Izabel dos Santos formou, no Estado do Rio de Janeiro, aproximadamente quatro mil, seiscentos e sessenta ACS, na primeira etapa do curso técnico acima mencionado.

Em 2008, a Escola Politécnica de Saúde Joaquim Venâncio (EPSJV) da Fiocruz iniciou uma turma piloto com as três etapas do Curso Técnico de Agente Comunitário de Saúde (CTACS) e, em 2011, em convênio com a Secretaria Municipal de Saúde e Defesa Civil do Rio de Janeiro, implementou as etapas II e III do CTACS, com um total de novecentas e vinte horas. O conteúdo curricular, organizado na forma de eixos temáticos, versava sobre temas como Estado e políticas públicas, cuidado e promoção em saúde, educação em saúde, vigilância em saúde, planejamento em saúde, comunicação e expressão.

Ao percorrer o currículo, os participantes, organizados em grupos, iam construindo o Trabalho de Conclusão de Curso (TCC), que deveria apresentar um Plano de Ação Educativa na comunidade. Para a elaboração do Plano de Ação, foi

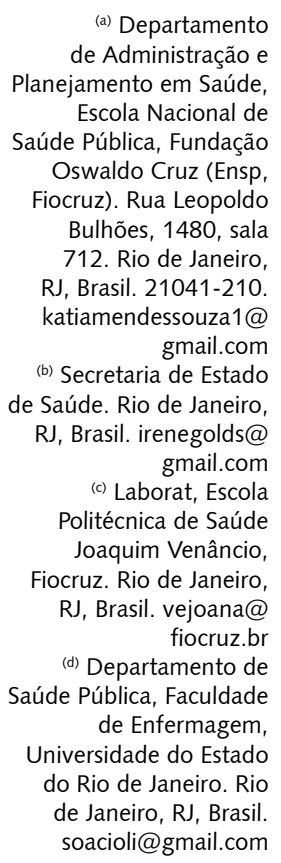
gmail.com (c) Laborat, Escola Politécnica de Saúde Joaquim Venâncio, Fiocruz. Rio de Janeiro, RJ,Brasil.vejoana@ fiocruz.br

(d) Departamento de Saúde Pública, Faculdade de Enfermagem, Universidade do Estado do Rio de Janeiro. Rio de Janeiro, RJ, Brasil. soacioli@gmail.com 
utilizado o Planejamento Estratégico em Saúde ${ }^{(e)}$ precedido pela elaboração de um diagnóstico situacional, que consistia no levantamento da situação de vida e de saúde no território, a partir da observação local e de entrevistas feitas pelos alunos aos moradores e profissionais de saúde da área.

Foram inscritos duzentos e dez ACSs que já haviam cursado a primeira etapa, divididos em sete turmas localizadas em diferentes territórios: Santa Cruz, Campo Grande, Bangu, Centro, Penha, Pavuna e Manguinhos, na EPSJV.

O corpo docente foi composto por um professor fixo para cada turma, diversos professores que apresentaram temas específicos e três preceptores, profissionais inseridos na estratégia saúde da família que acompanharam os alunos, no trabalho de campo e na elaboração do TCC. Além desse corpo docente para cada turma, existia também a coordenação pedagógica que acompanhava as diversas turmas.

O curso teve início em novembro de 2011 com término em 25 de janeiro de 2013, quando foi realizada uma grande mostra com apresentação dos trabalhos finais de curso de todos os ACSs.

O projeto político pedagógico da Escola Politécnica de Saúde Joaquim Venâncio tem como um de seus princípios básicos o conceito de politecnia, que questiona a dualidade entre ensino técnico e propedêutico, defendendo para o primeiro uma educação igualmente integral e crítica, que vá muito além do mero preparo técnico para a operacionalização do trabalho, incentivando a reflexão sobre os fundamentos científicos e filosóficos desses procedimentos.

Essa concepção se harmoniza com o referencial teórico-metodológico da Educação Popular, movimento que se configurou na década de 1970, como uma maneira de resistência ao autoritarismo do regime militar, desenvolvido por intelectuais das mais diversas áreas, apoiados pela Igreja Católica.

A Educação Popular visa, por meio da participação de educadores, intelectuais, cientistas sociais e profissionais da saúde, fomentar formas coletivas de aprendizado e de investigação, no sentido de fortalecer, nos educandos, a capacidade de análise crítica da realidade, incentivando o desenvolvimento da organização popular, em busca da reorientação da vida social na direção de uma sociedade mais equânime. Longe de se arvorar no papel de ditar comportamentos corretos, essa vertente pedagógica está sempre voltada para "problematizar, em uma discussão aberta, o que está incomodando e oprimindo"3 (p. 71).

O termo Educação Popular está associado a uma educação realizada nos movimentos populares, e é política na medida em que não se dissocia da vida cotidiana, que é o ponto de partida para a compreensão dos problemas que afligem a comunidade e para a compreensão sobre as estratificações sociais e de poder que a permeiam.

Para que o processo educativo em saúde realmente alcance os sujeitos, transformando suas práticas e concepções, não se pode ignorar nem menosprezar seu saber preexistente. Para Stotz, David e Bornstein ${ }^{4}$, compartilhar com a população a busca pelo entendimento da sua realidade, em toda a sua complexidade, é o ponto de partida para a elaboração e construção de novos conhecimentos:

Quando nos dispomos a ampliar o nosso próprio olhar para compreender o olhar da população, temos de optar por metodologias educativas que nos aproximem das pessoas, que lhes dêem voz, que as tornem mais fortes $\operatorname{como~sujeitos}^{4}$ (p. 44).

A proposta pedagógica baseou-se, principalmente, nas formulações de Paulo Freire, dentro da perspectiva de que todo indivíduo possui um saber, e que novos (e) Metodologia concebida pelo economista chileno Carlos Matus, que considera que planejar não é prever o futuro, mas sim trabalhar considerando a incerteza das variáveis que escapam à nossa vontade e poder. Isto pressupõe ter um plano e uma estratégia para distintos cenários previsíveis². 
conhecimentos se constroem a partir desses saberes prévios. Nessa perspectiva, antes de introduzir um tema novo, havia sempre a preocupação de procurar saber quais eram os conceitos prévios que os educandos já possuíam sobre o assunto. Freire ${ }^{5}$ nos indica como condição essencial ao processo educativo o respeito ao saber do outro, à sua experiência, quando diz que "o respeito à autonomia $e$ à dignidade de cada um é um imperativo ético e não um favor que podemos ou não conceder uns aos outros"5 (p. 66).

A Educação Popular foi a base para o curso e, dessa forma, a história e o pensamento de autores como Paulo Freire, Victor Valla, Eymard Vasconcelos e outros foram enfatizados para os educandos. Coerentemente, a relação educador-educando foi caracterizada pela criação de estratégias pedagógicas participativas e problematizadoras. A Educação Popular é considerada uma metodologia ativa de ensino-aprendizagem, pois propõe desafios para educandos, colocando-os no lugar de sujeitos na construção dos conhecimentos, ficando o educador como orientador desse processo $0^{6,7}$.

O objetivo do curso era fortalecer o papel educativo e mobilizador do ACS em seu território, visando à promoção da saúde, dentro da perspectiva da integralidade. A importância de utilizar a Educação Popular em Saúde para essa finalidade é destacada por autores como Albuquerque e Stotz ${ }^{8}$ :

O reconhecimento do usuário como cidadão nos grupos que não os estigmatizam como doentes, pois são ouvidos e estimulados a viver atividades de promoção da saúde (exercícios, alimentação, hábitos) e lutar em defesa de melhores condições de vida, representa fato concreto dificilmente encontrado em equipes que não se referenciam na educação popular. (p. 272)

Esse papel, esperado dos agentes comunitários pela própria Política Nacional de Atenção Básica9 , é dificultado pela cobrança do cumprimento de metas quantitativas, entre as quais não consta a realização de grupos educativos na comunidade. Essa tensão esteve presente ao longo de todo o curso e condicionou o seu desenvolvimento. Além disso, a gestão dos serviços municipais de saúde por organizações sociais de saúde gera uma grande rotatividade de profissionais nas equipes, não permitindo a garantia da continuidade de uma linha de trabalho.

Este artigo se propõe a fazer um relato de experiência com algumas reflexões sobre as principais práticas pedagógicas desenvolvidas nas turmas descentralizadas da Penha e da Pavuna do Curso Técnico de Agente Comunitário de Saúde da Escola Politécnica de Saúde Joaquim Venâncio, nas áreas programáticas, respectivamente, do município do Rio de Janeiro.

\section{A experiência na turma da Penha}

Composta por ACSs do Complexo do Alemão, Vigário Geral e Maré, a turma da Penha era bastante animada: crítica, polêmica, questionadora e propositiva. Além disso, era também heterogênea: faixa etária, que variava entre vinte e setenta anos; nível de formação, que variava entre a conclusão, concomitante ao CTACS, do ensino médio e nível superior, em Serviço Social e Administração; domínio de informática desde nulo até o de técnicas de elaboração de vídeos.

A fim de integrar todos os participantes no processo pedagógico, além da pactuação de frequência e assiduidade ao curso, foram realizados diversos momentos de confraternização com comemoração de aniversários; dia do ACS; passeio à Igreja da Penha, com leitura de texto sobre a história do local, foto para a Formatura, lanche coletivo; e confraternização no final do curso.

Após a pactuação da dinâmica do curso entre os participantes da turma da Penha, professora, preceptoras e educandos foram construindo espaços dialógicos de ensino-aprendizagem com inovações metodológicas e de conteúdos, partindo da realidade dos alunos para a teoria, a fim de voltar com uma prática transformadora. Foi utilizada uma abordagem participativa para o aprendizado, com dinâmicas e diversos tipos de materiais didáticos, tais como jogos gigantes, álbuns seriados, fantoches, revistas em quadrinhos, livros de história, macromodelos da boca e dentes, provérbios e poesias. 
Visando facilitar a aproximação dos ACSs com os textos de referência do curso, foram preparados resumos desses textos, com leitura em sala de aula e esclarecimento de dúvidas. Outro recurso utilizado foi a elaboração de roteiros de pesquisa a serem realizadas na Biblioteca Virtual em Saúde (BVS) sobre os temas de interesse dos educandos, facilitando sua prática investigativa.

Além disso, os planos de aula eram apresentados no início de cada eixo temático, com seus objetivos e atividades a fim de situar os educandos em cada etapa do processo de ensinoaprendizagem. A implementação da proposta da EPSJV sempre era adaptada à realidade da turma, o que possibilitou um grande aprendizado para todos os participantes. A flexibilização das propostas iniciais de trabalho abriram espaço para as propostas da turma, favorecendo o comprometimento permanente do grupo.

Para a construção coletiva de conceitos, tais como: modelos de atenção, cuidados em saúde e trabalho, buscamos partir da expressão livre de ideias dos educandos, seguida da complementação com os conceitos de outros autores. Como exemplo dessa construção coletiva, podemos citar a preparação de alguns slides sobre o conceito de cuidado em saúde com frases dos próprios educandos, produzidas ao longo das oito aulas iniciais sobre o tema. Os alunos ficaram muito satisfeitos ao se verem como autores dessas reflexões e olhares.

Os trabalhos em grupos, realizados com frequência e acompanhados de debates, construção coletiva de cartazes e apresentações, facilitaram o desenvolvimento da expressão oral dos educandos. Além disso, as estratégias lúdicas, com recorte de revistas e jornais, colagens, desenhos e dramatizações, valorizaram outras formas de expressão, além da verbal.

O espaço físico favorecia o processo de ensino-aprendizagem, com diversos recursos tecnológicos como datashow, conexão com internet, sala confortável e com ar-condicionado. A sala de informática tinha dez computadores conectados à internet e havia ainda uma saleta de leitura com dois laptops, o que facilitava a divisão para trabalhos em grupo.

Esses recursos audiovisuais foram utilizados em diversos momentos, havendo aulas com músicas, exibição de filmes e vídeo-debates. Os educandos também eram estimulados a criarem e apresentarem suas próprias produções. O incentivo à elaboração e apresentação de trabalhos, utilizando os recursos disponíveis, favoreceu a autonomia do educandos no ambiente de aprendizagem.

Os alunos prepararam vários vídeos sobre a história de suas comunidades para serem exibidos no Congresso Internacional da Rede Unida, realizado em 2012. A fim de apresentar esse conjunto de vídeos, a turma também elaborou um texto coletivo. A participação no evento com apresentação de trabalhos valorizou as experiências dos educandos e os estimulou para a realização de novas produções técnicas.

O constante espaço para análise e troca de experiências foi também povoado por queixas dos alunos em relação a seu processo de trabalho. Essa temática interferiu bastante na dinâmica do curso, uma vez que os alunos consideravam a proposta do curso contraditória em relação à realidade encontrada em seu trabalho. Eles se sentiam sobrecarregados pelas cobranças no trabalho e não tinham tempo para leitura e realização de atividades em casa.

Apesar de ter sido pactuada uma redução de metas a ser alcançada pelos ACSs, entre Sindicato dos Agentes Comunitários de Saúde, EPSJV e Secretaria Municipal de Saúde e Defesa Civil (SMSDC), o número de famílias a ser atendido e os turnos de "acolhimento" dentro da Unidade de Saúde não foram reduzidos. Nesse sentido, os agentes de saúde sentiam que não conseguiam alcançar a cobertura de sua área. A dificuldade em conciliar a carga horária do curso e do trabalho esteve presentes durante todo o tempo. Vários foram os momentos de catarse que possibilitaram aos agentes de saúde compreender que o problema não era individual, mas que, na realidade, muitas das dificuldades estavam vinculadas ao modelo de gestão.

Os educandos confidenciavam seus problemas pessoais e, ao longo do curso, a professora teve a oportunidade de conhecer a vida de grande parte dos alunos, que vêm de um contexto de vida permeado pela precariedade e pela violência, o que se reflete diretamente nas suas condições de saúde. Essa proximidade com os alunos possibilitou o acompanhamento, o apoio e o fortalecimento dos alunos na continuidade do curso e mesmo do trabalho. A postura profissional dialógica está em consonância 
com a perspectiva teórico-conceitual e metodológica da Educação Popular que permite fortalecer a atuação pedagógica dos profissionais, como mediadores e educadores $\operatorname{críticos}^{10}$.

Facilitado por essa abordagem, muitas dificuldades foram superadas e os educandos relataram uma superação pessoal no trabalho, na escrita, na expressão oral e na própria vida.

\section{A experiência na turma da Pavuna}

A turma da Pavuna reunia agentes de saúde moradores de bairros com os piores Índices de Desenvolvimento Humano (IDH) da cidade, como Costa Barros, Barros Filho, Fazenda Botafogo e Acari. Havia três alunas que residiam no Morro do Chapadão, zona altamente conflagrada, onde, ao longo do ano de 2012, ocorreram várias incursões policiais e tiroteios. Por esse motivo, elas tiveram que faltar à aula algumas vezes e apenas uma delas concluiu o curso.

O espaço onde ocorreu o CTACS foi a Clínica da Família Epitácio Soares Reis, na Pavuna, inaugurada em 05 de julho de 2011, quatro meses antes do início do CTACS. As aulas ocorriam no Centro de Cultura e Ideias, um auditório ovalado que permitia que as aulas ocorressem em círculo. O suporte de informática não era suficiente, havia dificuldade de acesso à internet e só havia computadores disponíveis na sala dos ACSs da própria Clínica. Essa situação nos fez buscar mais apoio em outros recursos didáticos.

A diversidade de procedência dos ACSs criou, no início, certo estranhamento. Eles se agrupavam na sala sempre nos mesmos lugares, pela proximidade de local de trabalho. Somente com o decorrer do tempo, ao longo das discussões coletivas, muitas vezes bem acaloradas, é que foi se desenvolvendo um espírito de união e solidariedade.

A temática mais recorrente desses debates era relativa ao processo de trabalho do ACS, com sete ou mais anos de trabalho, a relação com a equipe e gestores e a insegurança gerada pela precarização dos vínculos trabalhistas. Foi quase unânime a afirmação de que está havendo muitas mudanças no processo de trabalho da Saúde da Família, direcionado para o cumprimento de metas quantificadas, de ações e procedimentos, e que os agentes estão muito mais presos à unidade de saúde, com muito menos tempo para visitas domiciliares e atividades educativas. Essa visão pode ser identificada em textos escritos por eles:

\footnotetext{
"Mudou a visão, o propósito. Mudaram os direitos, os deveres. Mudou a sigla de quem era PACS para PSF. Uma enfermeira com 30 agentes comunitários dava conta de fazer visitas aos acamados, ações e palestras nas áreas e curativos. Hoje uma enfermeira com 6 agentes (ACS) não faz mais visita domiciliar, não tem tempo, agenda lotada, reuniões e cursos. E o ACS entregador de cartão e SISREG fica no Posso Ajudar, acolhimento, pesagem, bolsa família, alimentar o sistema, ficamos presos no posto. Não temos mais tempo para uma visita com qualidade sobre orientação e prevenção. Não temos mais aquele olhar olho-a-olho com as famílias. Acabou o vínculo. Só nos pedem números, saúde é número". (ACS 2)
}

No entanto, com todas as dificuldades e dramas pessoais (que não eram poucos), era uma turma muito alegre e adorava passeios, festas, almoços e confraternizações.

Como a estratégia era partir dos conhecimentos dos ACSs ao começar a discutir algum tema, foram propostos trabalhos em grupos, dramatizações, desenhos, exibição de filmes, e, a partir daí, buscávamos estabelecer ligações entre os conteúdos apresentados por eles com os saberes teórico-científicos vigentes.

A dramatização propiciou elementos para discussão a partir da análise do comportamento e postura daqueles que representam, pois expressam visões e ideias que talvez não se consigam expor oralmente, muitas vezes, não conscientes. Na situação dos alunos, a representação trouxe concepções do seu cotidiano de vida e de trabalho, possibilitando a participação coletiva nas discussões, já que o tema era familiar a todos.

Numa dessas dramatizações, pedimos que alguns grupos representassem uma visita domiciliar ideal, do ponto de vista do comportamento do ACS, e outros grupos deveriam apresentar uma visita domiciliar onde o comportamento do ACS era totalmente inadequado. Em outra dramatização, pedimos que os grupos apresentassem cenicamente suas concepções sobre "O Modelo de Saúde que 
temos" e, em seguida, "O Modelo de Saúde que queremos". A discussão era orientada no sentido de pensar: o que podemos fazer para ir do modelo que temos ao modelo que queremos.

A possibilidade de se expressar de uma forma mais livre e criativa sempre foi um incentivo, pelo aspecto lúdico que apresentava, abrindo horizontes para a percepção da realidade de várias formas e ângulos. Por exemplo, a utilização do desenho numa aula sobre família: foi pedido que cada aluno desenhasse a sua família, e depois apresentasse para a turma.

Essa aula possibilitou um maior autoconhecimento do grupo não só no campo racional, mas também no sensitivo-afetivo. Ficamos nos conhecendo melhor, sabendo, por exemplo, que determinada aluna tinha uma tartaruga, que considerava da família, já que a incluiu no desenho; ficamos sabendo quem era sozinho ou quem tinha família grande. Enfim, histórias da vida de cada um de nós. Esse formato da aula, partindo do pessoal e singular, despertou interessantes reflexões sobre o conceito de família e os vários tipos de família encontrados nas comunidades em que os agentes de saúde trabalham.

O professor de Oficina de Leitura organizou um júri onde foi julgado o bullying, com diversos papéis, como defesa, acusação, juiz, réus e testemunhas. Antes de iniciar o julgamento, ele falou sobre o que era esse conceito e trouxe reportagens e vídeos. A atividade estimulou os alunos a desenvolverem sua capacidade de argumentação, levando-os a se envolver profundamente, resultando em debates acalorados, abrangendo vários campos do conhecimento, como sociologia, psicologia, direito, ética e outros.

Também utilizamos esse formato para discutir os modelos assistenciais, por meio do julgamento do modelo biomédico. Alguns dos argumentos utilizados pela "defesa" foram que, no modelo biomédico (associado a hospital), o indivíduo é atendido diretamente pelo médico, não precisa passar pela triagem, nem depender do sistema de regulação para conseguir exames, enquanto que a "acusação" apontou para a perda do olhar sobre o indivíduo como um todo: a necessidade de acordar de madrugada para conseguir atendimento hospitalar, a superlotação dos hospitais, que não conseguem atender toda a demanda, aliado ao alto gasto com saúde que poderia ser diminuído se houvesse a promoção da saúde.

Embora a exibição de filmes seja uma prática bastante usual, é importante ressaltar o poder reflexivo que o filme possibilita, por trazer realidades diversas, de outras culturas, outros povos, e pela linguagem, que engloba várias formas de arte - representação, música, literatura, desenho, dança. Para incentivar a reflexão após o filme, foi utilizada a discussão coletiva e elaboração de textos individuais ou grupais sobre o tema.

Acerca do filme Notícias de uma Guerra Particular, sobre o tráfico de drogas no Rio de Janeiro selecionamos depoimentos de alguns alunos:

"O filme relata a violência em uma determinada comunidade do Rio de Janeiro, infelizmente não é uma ficção, é a dura realidade. Pessoas que vivem precariamente, sem saneamento, sem uma moradia digna e principalmente sem pensar ou sonhar com um amanhã melhor. Não devemos julgar as atitudes daquelas pessoas, mas sim tentar entender o que as leva a se comportarem daquela forma". (ACS3)

“Esse filme trata de vários fatores responsáveis pela guerra que vivemos. $1^{\circ}$ a desigualdade social, $2^{\circ}$ sociedade capitalista, $3^{\circ}$ corrupção policial. Eu acho que esses três fatores são responsáveis pela guerra porque a desigualdade social torna os meninos presas fáceis para o tráfico numa sociedade capitalista onde quem não tem um tênis Nike não é nada, e todos nós queremos ser aceitos". (ACS4)

Esses textos apontam para a profundidade das reflexões que os agentes de saúde conseguiram elaborar ao assistir ao filme e como construíram relações de causa e efeito, percebendo, além do senso comum, a essência que se oculta por trás da aparência. 


\section{A construção dos trabalhos de conclusão de curso}

Essa atividade se constituiu no eixo condutor de todo o curso, pois agregou conhecimentos de todas as áreas para pensar uma intervenção na realidade e possibilitou uma reflexão mais profunda sobre as possibilidades e limites concretos dessa intervenção. Os educandos tiveram a liberdade para escolher os temas que queriam desenvolver, a partir da construção do diagnóstico de saúde do seu território.

A orientação dos planos de ação, caracterizada por um processo de educação por intermédio de ações coletivas e mobilizando os atores locais para a luta pela cidadania, evidenciou, mais uma vez, a importância da utilização da Educação Popular como estratégia política para a atuação na Atenção Básica em Saúde ${ }^{11}$.

Tanto na turma da Penha quanto na da Pavuna, os educandos se sentiram realmente autores do trabalho, pois participaram ativamente de todo o processo. Desde o início, tiveram o aprendizado da escuta, realizando diversas entrevistas na comunidade.

Com o ritmo acelerado do curso, foi difícil realizar uma singularização do processo de aprendizagem dos educandos, mas com a divisão em grupos para o TCC, foi possível um acompanhamento diferenciado a cada grupo de quatro ou cinco pessoas.

Foi observado um início de mudança no conceito de Educação em Saúde. A partir da ênfase durante todo o curso nos princípios da Educação Popular, na escuta, na alteridade, foi incentivada e discutida a proposta de mudança de expressões como: conscientizando a comunidade para discutindo questóes com a comunidade.

Depois do TCC pronto, os educandos ficaram muito orgulhosos com o produto do seu trabalho e demonstraram, ainda, interesse no aprendizado de técnicas de comunicação para preparar as apresentações. O curso finalizou com a apresentação dos TCC das sete turmas, numa grande mostra realizada na EPSJV.

\section{Considerações finais}

A apresentação das principais práticas pedagógicas desenvolvidas no curso nos possibilita realizar uma reflexão analítica sobre a finalidade da Educação Popular em Saúde enquanto abordagem que privilegia o diálogo, pois "ampliar a compreensão de si e do mundo, na dimensão do diálogo, é pronunciar o mundo entre sujeitos. Portanto, é reconhecer que o outro também é sujeito, tem sua história, trajetória, valores"12 (p. 75).

Nesse sentido, os espaços de formação descritos promoveram o encontro de profissionais com o estímulo a uma postura crítica em relação a seu processo de trabalho, de forma alinhada com os princípios da Educação Popular, que se orientam por sempre discutir educação e direito à saúde de forma contextualizada. As estratégias de educação utilizadas, tal como o diagnóstico participativo no planejamento estratégico situacional, demonstraram que "a recusa em teorizar fora do contexto da ação é fonte de aproximação da vida social, em especial daqueles grupos sociais mais oprimidos"13 (p. 50).

Ainda que sejam lentas as melhorias e transformações no contexto de vida e de trabalho do Agente Comunitário de Saúde, a formação possibilitou a vivência de mediações de forma horizontal, favorecendo processos de vocalizações de anseios, demandas e proposições, contrastando com a lógica hegemônica vertical e hierárquica das interações na sociedade. Essa reorientação na construção de vínculos e relações é imprescindível para mudanças em suas condições de vida e trabalho, pois:

o caráter transformador da mediação se daria quando houvesse uma ruptura desta verticalidade, para que existisse maior compartilhamento do conhecimento e maior permeabilidade dos serviços quanto às necessidades e demandas da população. ${ }^{14}$ (p. 479)

Como avaliação do curso, retomamos o cerne da questão do CTACS, colocada na introdução: a tensão entre a proposta político-pedagógica do curso e o modelo de gestão atual da SMSDC do Rio de 
Janeiro. Os trabalhos produzidos pelos ACSs ao longo do curso trouxeram à luz o lugar em que esse trabalhador se vê, como um ponto de convergência de tensões e conflitos. A percepção desses agentes sobre as mudanças no seu processo de trabalho foram enriquecidas pelas reflexões desenvolvidas durante o curso, nesse momento histórico particular em que a Estratégia de Saúde da Família vem enfrentando mudanças não só no município do Rio de Janeiro, mas em todo país.

São tensionamentos cujos princípios basilares da atenção básica, que são também os do SUS, como a importância da construção de vínculos, de responsabilização pela população de um território com o seu acompanhamento dentro da rede de atenção, da escuta, da garantia de acesso, do atendimento humanizado, vêm perdendo espaço para os princípios neoliberais, sendo os trabalhadores da saúde submetidos à pressão para apresentar produtos e atingir metas quantificadas, independentemente da realidade local, dentro do contexto da privatização/terceirização da gestão pública e da precarização dos vínculos de trabalho.

O CTACS propiciou a oportunidade de um grande aprendizado coletivo de educandos e educadores.

Aprendemos com os educandos ainda mais sobre a integralidade no processo educativo, a forma como os valores e as questões pessoais estão envolvidos no aprendizado. Aprendemos com eles ainda mais alegria, leveza, espontaneidade, simplicidade, flexibilidade, dinamismo, presteza, solidariedade; valores e sabedoria sem os quais é impossível superar os problemas encontrados.

Percebemos também o fortalecimento e o desenvolvimento do prazer do trabalho coletivo e a criação de laços de amizade entre colegas de diferentes áreas e de um convívio afetuoso em sala de aula. Além disso, o dimensionamento da influência de seu trabalho, com a compreensão de fatores externos que condicionam determinadas situações e a percepção sobre a necessidade de uma postura propositiva na vida e no trabalho, não apenas queixosa e questionadora.

Concluímos que a abordagem adotada no CTACS levou em conta os saberes e as experiências de todos os envolvidos no processo, baseando-se na construção compartilhada do conhecimento.

Compreende-se que a abordagem de construção desse novo saber, com metodologias da Educação Popular, reflete um mosaico de saberes de diferentes sujeitos, ganha força e legitima a identidade do grupo para ser aplicado na prática, possibilitando novas posturas e comportamentos de enfrentamento para as questões priorizadas no território.

\section{Colaboradores}

Os autores Kátia Mendes de Souza e Irene Leonore Goldschmidt participaram, igualmente, da elaboração do artigo, de sua discussão e redação e da revisão do texto. Vera Joana Bornstein e Sonia Acioli participaram da revisão bibliográfica, de discussões e revisão do texto.

\section{Referências}

1. Ministério da Saúde. Ministério da Educação. Referencial curricular para curso técnico de agentes comunitários de saúde: área profissional saúde. Brasília, DF: Ministério da Saúde; 2004.

2. Huertas F. O método PES: entrevista com Matus. São Paulo: Fundap; 1996.

3. Vasconcelos EM. Educação Popular: de uma prática alternativa a uma estratégia de gestão participativa das políticas de saúde. Physis. 2004;14(1):67-83.

4. Stotz EN, David HMSL, Bornstein VJ. Educação popular em saúde. In: Martins CM, Stauffer AB, organizadores. Educação e Saúde. Rio de Janeiro: EPSJV/Fiocruz; 2007. p. p. 35-70. (Coleção Educação Profissional e docência em saúde: a formação e o trabalho do agente comunitário de saúde; 6).

5. Freire P. Pedagogia da autonomia: saberes necessários à prática educativa. São Paulo: Paz e Terra; 1996.

6. Freire P. Pedagogia do oprimido. São Paulo: Paz e Terra; 1987. 
7. Bordenave JD, Pereira AM. Estratégias de ensino-aprendizagem. Petrópolis: Vozes; 1994.

8. Albuquerque $\mathrm{PC}$, Stotz EN. A educação popular na atenção básica à saúde no município: em busca da integralidade. Interface (Botucatu). 2004;8(15):259-74.

9. Ministério da Saúde. Secretaria de Atenção à Saúde. Departamento de Atenção Básica. Política Nacional de Atenção Básica [Internet]. Brasília (DF): Ministério da Saúde; 2012 [acesso 2013 Set 2]. Disponível em: http://189.28.128.100/dab/docs/publicacoes/geral/pnab.pdf.

10. Stotz EN, David HMSL, Bornstein VJ. O agente comunitário de saúde como mediador: uma reflexão na perspectiva da educação popular em saúde. Rev APS. 2009;12(4):487-97.

11. Malfitano APS, Lopes RE. Educação Popular, ações em saúde, demandas e intervenções sociais: o papel dos agentes comunitários de saúde [Internet]. Cad Cedes. 2009;29(79):361-72 [acesso 2013 Set 2]. Disponível em: http://www.cedes.unicamp.br

12. Oliveira MW. Educação popular e saúde. Rev Educ Pop. 2007;6:73-83.

13. Stotz EN, David HMSL, Un JAW. Educação Popular e Saúde: trajetória, expressões e desafios de um movimento social. Rev APS. 2005;8(1):49-60.

14. Bornstein VJ, Stotz EN. O trabalho dos agentes comunitários de saúde: entre a mediação convencedora e a transformadora. Trab Educ Saude. 2008/2009;6(3):457-80. 
Este artigo discute as práticas pedagógicas desenvolvidas no Curso Técnico de Agente Comunitário de Saúde (ACS) da Escola Politécnica de Saúde Joaquim Venâncio, nas turmas da Penha e da Pavuna, no município do Rio de Janeiro. O referencial teórico-metodológico do curso baseia-se nos princípios da Educação Popular. Dessa forma, a relação educador-educando caracterizou-se pela criação de estratégias pedagógicas participativas e problematizadoras. Buscou-se o diálogo e a problematização da prática dos educandos junto à equipe de saúde, usuários e gestores da estratégia de saúde da família. O uso dessas práticas pedagógicas, desenvolvidas a partir dos saberes e experiências de educandos e educadores, demonstrou favorecer a construção de um olhar crítico para as contradições existentes entre os princípios da Política Nacional de Atenção Básica e o modelo atual de gestão da estratégia de saúde da família.

Palavras-chave: Educação Popular em Saúde. Metodologia. Formação de Agentes Comunitários de Saúde. Sistema Único de Saúde.

\section{Pedagogical practices of Popular Health Education and technical training of Community Health Agents in the city of Rio de Janeiro, Brazil}

This article discusses the pedagogical practices developed in the Technical Training Course of Community Health Agents (CHA) of Joaquim Venancio Polytechnic Health School, in classes held in the districts of Penha and Pavuna in the city of Rio de Janeiro. The theoretical and methodological references of the course are based on the principles of Popular Health Education. Thus, the relationship between teacher and students was characterized by the creation of participative pedagogical strategies. Problem-based learning was developed to analyze with students their experience with the health care team. We conclude that the use of strategies developed from and based on students' knowledge favors a discussion of the tension which exists between the Primary Health National Policy and the current family health strategy management.

Keywords: Popular Education in Health. Methodology. Community Health Agents Training. Unified National Health System.

\section{Practicas pedagogicas en Educación Popular en Salud y la formación técnica de Agentes Comunitarios de Salud en el municipio de Rio de Janeiro, Brasil}

Este artículo discute las practicas pedagógicas desarrolladas en el Curso Técnico de Agente Comunitario de Salud de la Escuela Politécnica de Salud Joaquim Venâncio, en dos barrios de Rio de Janeiro. El referencial teórico-metodológico del curso se basa en los principios de la Educación Popular. La relación educador-educando se caracterizó por la creación de estrategias pedagógicas participativas y problematizadoras. Se buscó el diálogo y la problematización de la práctica de los educandos junto al equipo de salud, usuarios y gestores de la estrategia de salud. La utilización de estas prácticas pedagógicas desarrolladas a partir de los saberes y experiencias de educandos y educadores, demostró favorecer la construcción de una mirada crítica para las contradicciones existentes entre los principios de la Política Nacional de Atención Básica y el actual modelo de gestión de la estrategia de salud de la familia.

Palabras clave: Educación Popular en Salud. Metodología. Formación de Agente Comunitario de Salud. Sistema Único de Salud. 